\title{
Análise microestrutural de matrizes cimentícias com baixo teor de cimento
}

\section{Microstructural analysis of cementitious matrices with low cement content}

\author{
Marco Antonio Campos ${ }^{1 *}$, Luciano Passos ${ }^{2}$, André Munhoz de Argollo Ferrão ${ }^{2}$, Armando \\ Lopes Moreno Júnior ${ }^{2}$
}

\begin{abstract}
RESUMO
As matrizes cimentícias com baixo teor de cimento são caraterizados pela combinação média de $70 \%$ de cimento Portland e 30\% de material pozolânico. Considerando os materiais pozolânicos alternativos os resíduos cerâmicos e a sílica ativa são materiais que de início atendem os quesitos de utilização devido a similaridade entre seus constituintes, índice de atividade pozolânica e principalmente controle da origem e granulometria. Combinado sílica ativa e fíler de resíduos cerâmicos de isoladores elétricos de porcelana e de cerâmica vermelha, como material pozolânico nas matrizes cimentícias, mostrou ser uma prática viável, como foi observado nos ensaios de caracterização inicial, resistência à compressão simples e na análise microestrutural conferindo resistência e formação dos compostos de hidratação similares a matriz cimentícia com $100 \%$ de cimento. Assim, obtém-se matrizes cimentícias de baixo teor de cimento, combinado $70 \%$ de cimento Portland e 30\% de fílers cerâmicos e sílica ativa com as mesmas características e propriedades que a convencional.
\end{abstract}

Palavras-chave: Matriz cimentícia; Sílica ativa; Fíler cerâmico; Isolador de porcelana; Resíduo cerâmico.

\section{ABSTRACT}

Low cementitious matrices are characterized by an average combination of $70 \%$ Portland cement and $30 \%$ pozzolanic material. The alternative pozzolanic materials, ceramic residues and silica fume are materials that meet the usage requirements due to the similarity among their constituents, pozzolanic activity index, and especially the control of their origin and granulometry. The combination of silica fume and filler from porcelain and red ceramic electrical insulator waste, as a pozzolanic material in cementitious matrices, is a viable practice, as was observed in the initial characterization tests, resistance to simple compression and in the microstructural analysis, conferring strength and formation of hydration compounds similar to a cement matrix with $100 \%$ cement. This results in cementitious matrices with low cement content, combined $70 \%$ Portland cement and $30 \%$ ceramic fillers and silica fume, with the same characteristics and properties as conventional ones.

Keywords: Cementitious matrix; Silica fume; Ceramic filler; Porcelain insulator; Ceramic residue.

\footnotetext{
${ }^{1}$ Consultor em Engenharia Civil e em Materiais de Construção Alternativos.

*E-mail: engenheiromarcoantonio@ hotmail.com

${ }^{2}$ Faculdade de Engenharia Civil, Arquitetura e Urbanismo da Universidade Estadual de Campinas FECFAU-UNICAMP.
} 


\section{INTRODUÇÃO}

Formada por aglomerantes minerais, em especial o cimento Portland, as matrizes cimentícias podem receber agregados resultando em pastas, argamassas e concretos. Portanto, define-se matriz cimentícia como a parte aglomerante de uma argamassa, isto é, o material que em contato com água resulta em produtos hidratados que conferem resistência. Tem-se, com isso, o cimento Portland como o material aglomerante mais empregado para atender estas condições.

Devido a esta versatilidade e grande utilização o cimento Portland foi o responsável pelos avanços tecnológicos da construção civil que permitiram a construção de edifícios cada vez altos, pavimentos mais resistentes e obras mais duráveis, por exemplo. Entretanto, não é apenas o uso do cimento que resulta nestes benefícios, pois vários fatores impactam diretamente em suas propriedades como o seu teor máximo, a relação água/cimento, granulometria e local de aplicação. Soma-se a estes fatores as características, propriedades e tipos dos agregados utilizados.

Em contrapartida a esses benefícios da utilização do cimento a indústria cimenteira constitui-se em uma das maiores fontes poluidoras do planeta. $\mathrm{O}$ crescimento populacional induz ao aumento da demanda por novas habitações e unidades comerciais e industriais, além de toda a infraestrutura física do território. Assim, o consumo de cimento, e a dependência desse material aglomerante na construção civil é cada vez maior.

A utilização de elevados teores de cimento em concretos e argamassas contribui para o aumento da poluição ambiental, no entanto, há outros tópicos referentes às suas estruturas e propriedades a serem considerados.

A hidratação do cimento é de natureza exotérmica, isto é, libera grande quantidade de calor o que pode comprometer grandes peças de concreto em barragens, blocos de fundação, paredes e pilares, e volumes de argamassas como o revestimento de paredes e fachadas de grandes dimensões.

Com o calor há a dilatação térmica, aumento do volume, seguido do resfriamento e retração, podendo causar fissuras, pois o concreto e a argamassa apresentam baixas resistências à tração. Estas fissuras podem ser o caminho preferencial a ser percorrido pela penetração de ar, água e agentes agressivos comprometendo toda a estrutura (REBMANN, 2011).

Muitas pesquisas acadêmicas buscam soluções para a diminuição do teor de cimento e consequente diminuição da poluição ambiental através da incorporação de materiais alternativos em substituição ao cimento.

Nesse grupo de materiais destacam-se as pozolanas e as cinzas, porém, estudos recentes referem-se a utilização de sílica ativa e materiais cerâmicos devido principalmente a similaridade entre seus componentes, obtendo os mesmos padrões de qualidade, trabalhabilidade, resistência e durabilidade. 
A sílica ativa é um resíduo da produção de silício ou ligas de ferro-silício, com o $\mathrm{SiO}_{2}$, expelido na forma de fumaça, se condensando em finas partículas esféricas altamente reativas, acelerando a reação com o $\mathrm{Ca}(\mathrm{OH})_{2}$. Por possuir grãos muito finos a sílica ativa pode preencher o espaço entre os grãos de cimento, melhorando o empacotamento e consequente resistência (NEVILLE; BROOKS, 2013).

Com todos estes pontos a sílica ativa é um material altamente pozolânico, mas de difícil manuseio, pois aumenta a necessidade de água no concreto, que pode ser contornada com a adição de aditivos redutores de água (MEHTA; MONTEIRO, 2008).

Outro material finamente moído utilizado em concretos é o fíler, que resulta em benefícios nas propriedades de trabalhabilidade, massa específica, permeabilidade, exsudação capilar e tendência à fissuração (MEHTA; MONTEIRO, 2008). Sua fonte pode ser de materiais de origem natural ou materiais processados inorgânicos. No Brasil o fíler pode ser utilizado na composição de cimentos Portland compostos, até o limite de 10\% (DAL MOLIN, 2005).

Assim como a sílica ativa o fíler também contribui para o aumento do teor de água no concreto, afetando negativamente a resistência do concreto ao intemperismo ou a proteção às armaduras. De natureza inerte o fíler não causa diminuição da resistência do concreto à longo prazo (NEVILLE; BROOKS, 2013).

Apesar destes pontos negativos em relação a utilização de sílica ativa e fílers, seu uso vem crescendo no Brasil nos últimos anos, sendo uma importante alternativa para o reaproveitamento de alguns materiais oriundos do processo fabril, do controle de qualidade ou de substituição. Com o avanço das pesquisas todos estes fatores deletérios são contornados com estudo de traço, incorporação de aditivos e melhores práticas nos canteiros de obras.

A escolha dos tipos de fíler a ser utilizado deve-se a fatores como disponibilidade, facilidade de beneficiamento e principalmente seu índice de atividade pozolânica.

Os resíduos cerâmicos, por serem produzidos com matérias-primas similares ao cimento, passarem pelo processo de queima, e com elevado volume são de início indicados para aplicação em matrizes cimentícias de baixo teor de cimento Portland.

A escolhas dos resíduos de telhas cerâmicas e de isoladores elétricos de porcelana atendem estes quesitos, além de serem abundantes na região onde esta pesquisa se desenvolveu, cidade de Campinas, no interior de São Paulo, pois tem-se em um raio de $100 \mathrm{~km}$ a cidade de Pedreira concentrando $80 \%$ da produção nacional de isoladores de porcelana (CAMPOS, 2018), e os polos cerâmicos de Rio Claro - Santa Gertrudes, Itu e Mogi Mirim na produção de pisos, blocos e telhas cerâmicas (SÃO PAULO, 2021).

Inúmeros são os trabalhos que comprovam, experimentalmente, a possibilidade da incorporação de resíduos de cerâmica vermelha, seja como agregado, em concretos e argamassas, seja como aglomerante, na substituição do cimento em matrizes cimentícias, devido a sua propriedade pozolânica, similaridade de matérias-primas e por não alterar as propriedades físicas, 
mecânicas e de durabilidade (SALES; ALFERES FILHO, 2014; CARVALHO, 2016; PASSOS, 2019).

Usos específicos dos resíduos de cerâmica podem ser encontrados na forma de agregado em pavimentação (DIAS, 2004), como substituto da areia em concretos utilizados na confecção de estacas (WADA, 2010) e até mesmo na produção de novos produtos cerâmicos como a substituição da argila por este resíduo (GOUVEIA, 2008) obtendo em todos os casos similaridade nas propriedades entre os materiais alternativos (resíduos) com os tradicionais.

Os resíduos de isoladores elétricos de porcelana - IEP, peças cerâmicas com elevada vida útil, não possuem até o momento uma metodologia difundida de reaproveitamento devido a fatores como dificuldade de moagem e pequeno volume, da ordem de 30.000 ton/ano, se comparado aos resíduos de cerâmica vermelha (CAMPOS et al., 2019).

Pesquisas anteriores comprovaram a utilização dos isoladores de porcelana em substituição aos agregados em concretos e argamassas, obtendo valores de resistência à compressão simples, dependendo do traço, superiores a um traço de referência (PORTELA et al., 2006; CAMPOS, 2018).

Outros trabalhos indicam a utilização dos IEP como material aglomerante a matriz cimentícia do cimento Portland. As imagens de MEV nestes trabalhos indicam que os compostos de hidratação do cimento Portland estão em consonância a bibliografia e com as observações nos traços de concreto e argamassa de referência, assim não há interferia dos IEP na hidratação da matriz cimentícia (BERALDO; SHIROMA; FERREIRA, 2014; SHIROMA, 2016, CAMPOS, 2018; CAMPOS et al., 2019).

A confecção de blocos de concreto combinado areia de descarte de fundição e isoladores de porcelana foi comprovada, visto que os blocos apresentaram resultados em atendimento as normas brasileiras vigentes (CAMPOS, 2018). Outro uso para os resíduos de isoladores elétricos de porcelana foi comprovado como argamassa colante para peças cerâmicas (SOARES, 2016), e como argamassa de piso autonivelante (PERREIRA, 2019).

Portanto, é válida de início a utilização de resíduos de IEP em substituição aos agregados em argamassas, e pelo fato de presentarem potencial atividade pozolânica podem ser utilizados como material aglomerante em matrizes cimentícias de baixo teor de cimento Portland.

Portanto, o objetivo geral deste trabalho foi estudar a diminuição da quantidade de cimento Portland, em matrizes cimentícias e sua aplicação em argamassas, substituindo-o por uma combinação de sílica ativa e fílers cerâmicos, comparando-as a um traço referência e em conformidade com as normas brasileiras. A quantidade de cimento foi fixada em $70 \%$, com $10 \%$ de sílica ativa e $20 \%$ de fíler.

Dois foram os tipos de fílers cerâmicos utilizados, um resultante da moagem de isoladores elétricos de porcelana e outro de resíduos da indústria de telhas cerâmicas, ambos moídos em granulometria similar ao cimento. A escolha destes decorreu do fato de serem produzidos com 
matérias-primas similares a do cimento Portland, seu processo de produção envolver a queima em altas temperaturas o que pode conferir atividade pozolânica, ser um resíduo com controle de procedência e não possuir material contaminante ou de outra natureza.

Definidos os teores de sílica e fíler os traços de argamassas foram ensaiados a resistência à compressão simples nas idades de 7 e 28 dias, comparando seus resultados a um traço de referência, isto é, com 100\% de cimento. Observou-se que o aumento da idade resulta em maiores ganhos de resistência para as matrizes cimentícias alternativas permitindo sua utilização e comprovando a eficácia da substituição de $30 \%$ do cimento Portland por $10 \%$ de sílica ativa e $20 \%$ de fílers cerâmicos.

Através da análise microestrutural foi possível identificar os compostos da hidratação do cimento tanto no traço referência como nos traços com fílers cerâmicos, o que mostra que além do aumento de resistência estas substituições do cimento por fílers cerâmicos e sílica ativa possuem as mesmas características que a matriz cimentícia convencional.

\section{MATERIAIS E MÉTODOS}

Os materiais utilizados neste trabalho foram caracterizados inicialmente em relação a sua composição através dos ensaios de MEV/EDS: cimento Portland CPV-ARI - Alta Resistência Inicial, Figura 1 (a); Agregado miúdo comum, areia média, Figura 1 (b); Sílica ativa, da marca TecnoSil, Figura 1 (c); Fíler de cerâmica vermelha, telha cerâmica moída, Figura 1 (d); Fíler de cerâmica branca, isolador elétrico de porcelana moído, Figura 1 (e).

O agregado miúdo, a sílica ativa e os fílers cerâmicos possuem grande quantidade do composto silício ( $\mathrm{Si}$ ) que combina com o oxigênio e resultando no dióxido de silício, sílica $\left(\mathrm{SiO}_{2}\right)$ que é de extrema importância para hidratação do cimento e consequente aumento de resistência, quando em conjunto com o $\mathrm{CaO}$, presente no cimento, na formação do composto C-S-H.

$\mathrm{O}$ isolador elétrico de porcelana utilizado nesta pesquisa é proveniente do controle de qualidade fabril da cerâmica, portanto, é uma peça que não recebeu a haste metálica e não foi aplicado a material fixador desta haste no corpo cerâmico. Nestas condições foram utilizados apenas os corpos de porcelana.

A partir destes dados e de acordo com o traço de argamassa apresentado na NBR 7215 (1996), denominado traço referência, foi possível determinar o teor máximo de utilização do cimento Portland nas matrizes cimentícias, que foi fixado em $70 \%$. O teor restante de $30 \%$ material aglomerante foi dividido em $10 \%$ para a sílica ativa e $20 \%$ para o fíler cerâmico, ambos teores substituídos em massa, conforme Tabela 1. 
Tabela 1 - Composição traços

\begin{tabular}{|c|c|c|c|c|}
\hline Traço & $\begin{array}{c}\text { Cimento } \\
\text { Portland }\end{array}$ & $\begin{array}{c}\text { Sílica } \\
\text { Ativa }\end{array}$ & $\begin{array}{c}\text { Fíler } \\
\text { cerâmica }\end{array}$ & $\begin{array}{c}\text { Fíler de } \\
\text { porcelana }\end{array}$ \\
\hline Referência & $100 \%$ & - & - & - \\
\hline Fíler Cerâmica & $70 \%$ & $10 \%$ & $20 \%$ & - \\
\hline Fíler Porcelana & $70 \%$ & $10 \%$ & - & $20 \%$ \\
\hline Mix Fíler & $70 \%$ & $10 \%$ & $10 \%$ & $10 \%$ \\
\hline
\end{tabular}

Fonte: Elaboração dos autores, 2022.

Figura 1 - EDS Cimento Portland CPV-ARI (a), Areia (b), Ś́lica ativa (c), Fíler cerâmica vermelha (d), Fíler porcelana (e).

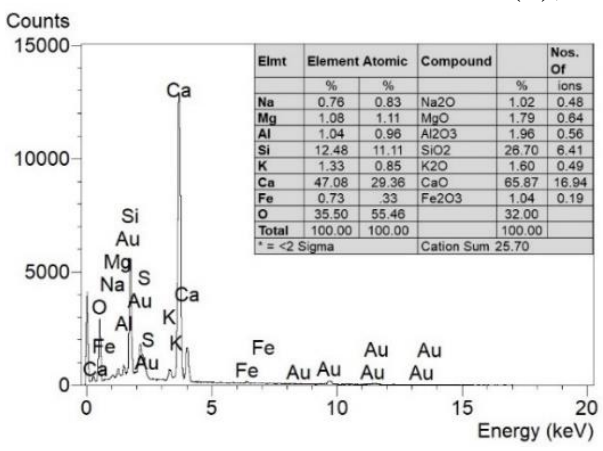

(a)

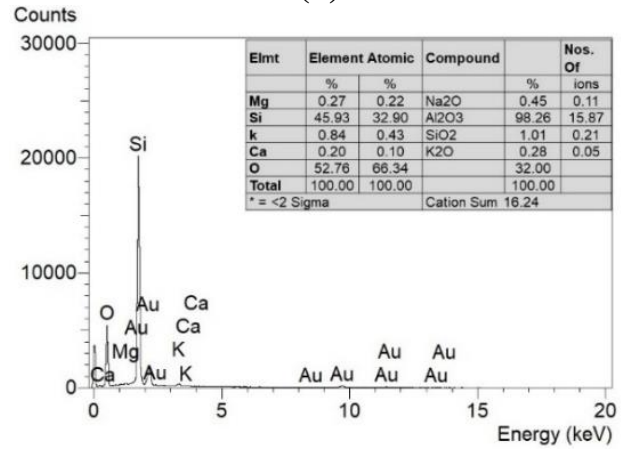

(c)

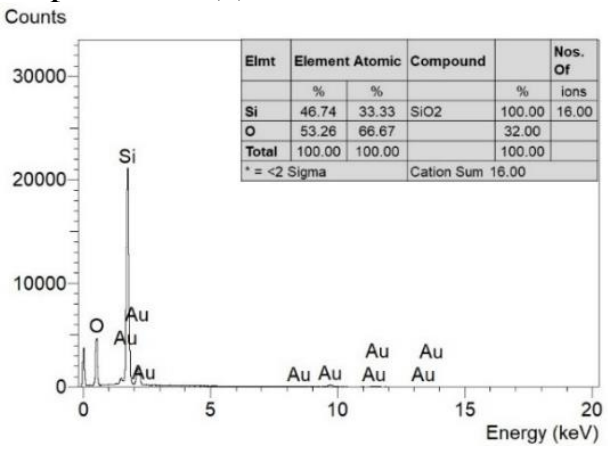

(b)

Counts

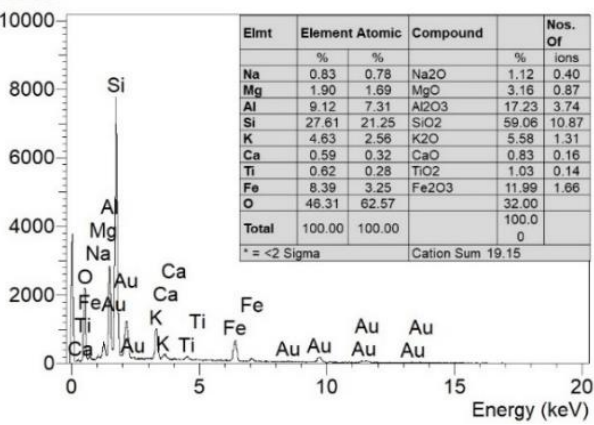

(d)

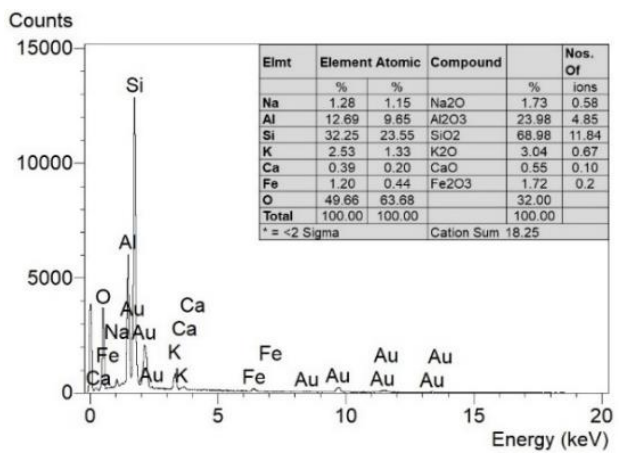

(e)

Fonte: Campos et al. (2019)

A Tabela 2 ilustra as quantidades de materiais necessárias para moldar quatro corpos-deprova cilíndricos de argamassa de 5,0x10,0 cm em atendimento a NBR 7215 (1996), norma que também preconizou o processo de moldagem. A relação água-cimento foi fixada em 0:55 para todos os traços. A cura foi do tipo submersa, isto é, os corpos-de-prova, após a desmoldagem, foram mantidos submersos em água até 24 horas antes de sua ruptura. 
Tabela 2 - Quantidade de materiais em gramas para os traços de argamassa.

\begin{tabular}{|c|c|c|c|c|c|c|}
\hline Traço & $\begin{array}{c}\text { Cimento } \\
\text { Portland }\end{array}$ & $\begin{array}{c}\text { Sílica } \\
\text { Ativa }\end{array}$ & $\begin{array}{c}\text { Fíler } \\
\text { cerâmica }\end{array}$ & $\begin{array}{c}\text { Fíler de } \\
\text { porcelana }\end{array}$ & $\begin{array}{c}\text { Agregado } \\
\text { miúdo }\end{array}$ & Água \\
\hline Referência & 624,00 & - & - & - & $1.872,00$ & 343,20 \\
\hline Fíler Cerâmica & 436,80 & 62,40 & 124,80 & - & $1.872,00$ & 343,20 \\
\hline Fíler Porcelana & 436,80 & 62,40 & - & 124,80 & $1.872,00$ & 343,20 \\
\hline Mix Fíler & 436,80 & 62,40 & 62,40 & 62,40 & $1.872,00$ & 343,20 \\
\hline
\end{tabular}

Fonte: Campos et al. (2019)

Definido estes traços foram realizados os ensaios de caracterização das misturas de materiais pozolânicos das matrizes cimentícias alternativas comparando-as a referência (100\% de cimento) quanto a massa específica, NBR 16605 (2017), finura por meio da peneira $75 \mu \mathrm{m}$, NBR 11579 (2012) e determinação da finura pelo método de permeabilidade ao ar (Blaine) NBR 16372 (2015).

Todos estes resultados são apresentados na Tabela 3, onde tem-se uma similaridade entre os resultados, apenas o teor de material passante na peneira $75 \mu \mathrm{m}$ foi maior para as misturas, mas isso já era esperado pois tanto a sílica ativa como os tipos de fíler possuem um grau de moagem superior ao cimento Portland.

Tabela 3 - Caracterização misturas sílica e fíler.

\begin{tabular}{|l|c|c|c|c|}
\hline Caracterização & $\begin{array}{c}\text { Cimento } \\
\text { Portland CPV - } \\
\text { ARI }\end{array}$ & $\begin{array}{c}\text { Sílica e Fíler } \\
\text { Porcelana }\end{array}$ & $\begin{array}{c}\text { Sílica e Fíler } \\
\text { Cerâmico }\end{array}$ & $\begin{array}{c}\text { Mix } \\
\text { Fíler }\end{array}$ \\
\hline Finura Blaine $\left(\mathrm{cm}^{2} / \mathrm{kg}\right)$ & 4.306 & 4.488 & 4.061 & 4.213 \\
\hline Massa Específica $\left(\mathrm{g} / \mathrm{cm}^{3}\right)$ & 3,11 & 2,84 & 3,01 & 2,93 \\
\hline Finura Peneira $75 \mu \mathrm{m}(\%)$ & 0,4 & 16,8 & 22,4 & 19,2 \\
\hline
\end{tabular}

Fonte: Campos et al. (2019)

\section{RESULTADOS E DISCUSSÃO}

Os traços de argamassa foram ensaiados à resistência à compressão simples nas idades de 7 e 28 dias, figura conforme a NBR 7215 (1996). Na Figura 2 tem-se a representação em gráfico dos valores médios destas resistências.

Para a idade de 7 dias o traço com fíler de isolador de porcelana apresentou maior resistência entre todos os traços, com a carga de ruptura maior que o traço referência, com cerca de $20 \%$. Já as argamassas com fíler cerâmico e o mix de fílers, os resultados foram inferiores à $17 \%$ e $4 \%$, respectivamente.

Já para a idade de 28 dias as diferenças nas resistências à compressão simples foram mais próximas entre si. Novamente, o traço com fíler de porcelana obteve resistência superior de $11 \%$, 
e para a argamassa com o mix de fíler cerâmico o valor similar a referência, e novamente o traço com fíler cerâmico o valor médio foi $7 \%$ inferior à referência.

Ao analisar a evolução da resistência à compressão simples de cada traço de argamassa em separado, isto é, comparando o valor inicial aos 7 dias de idade a idade final de 28 dias, observa-se que o traço com fíler de isolador de porcelana, apesar de ter obtido as maiores resistências, apresentou a menor evolução, de 6,6\%, destacada principalmente pela rápida atividade pozolânica deste tipo de cerâmica.

Figura 2 - Resistência à compressão simples.

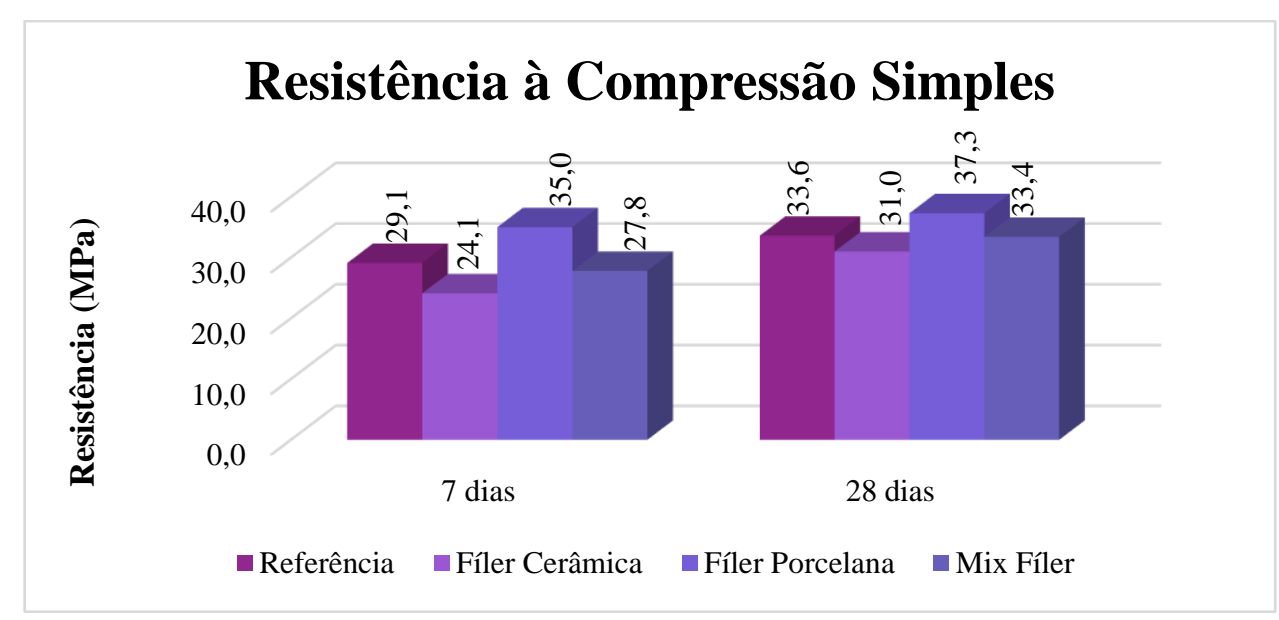

Fonte: Adaptado Campos et al. (2019)

O traço referência apresentou aumento de resistência de $15 \%$ entre os 7 e 28 dias. Os dois traços que se destacaram como as maiores elevações de resistência à compressão simples foram o traço com mix de fílers cerâmicos com $20 \%$ e o maior aumento foi para o traço de fíler de cerâmica vermelha com $28 \%$.

Estes aumentos de resistência podem ser explicados pela atividade pozolânica tardia, resultante da combinação da sílica ativa, cimento e fíler cerâmico, principalmente o fíler proveniente de telhas cerâmicas. Já para o traço referência e com fíler de isolador de porcelana esta atividade pozolânica se desenvolveu nas primeiras idades e está de acordo com o tipo de cimento utilizado.

Os ensaios de microscopia eletrônica de varredura (MEV) aos 28 dias de idade foram realizados no equipamento Microscópio Eletrônico de Varredura com Detector de Energia Dispersiva de raios X, Modelo do MEV: Leo 440i, Modelo do EDS: 6070, Marca MEV/EDS: LEO Electron Microscopy/Oxford (Cambridge, Inglaterra) disponível no Laboratório de Caracterização de Biomassa, Recursos Analíticos e de Calibração da Faculdade de Engenharia Química da Unicamp. 
Através da verificação da análise microestrutural destes traços de argamassa com matrizes cimentícias com baixo teor de cimento foi possível identificar o motivo deste aumento de resistência para as argamassas com sílica ativa e fíler cerâmico, que foi a identificação dos mesmos compostos de hidratação do cimento em todos os traços estudados, para a idade ensaiada de 28 dias.

Para o traço referência foram verificados os compostos etriginta $(\mathrm{E})$, portlandita $(\mathrm{CH}) \mathrm{e}$ C-S-H, Figura 3 (a), além da presença destes na zona de transição (ZT) agregado-pasta, e até seu crescimento sobre o agregado (Ag), Figura 3 (b).

Figura 3 - Compostos de hidratação MEV traço de argamassa referência.

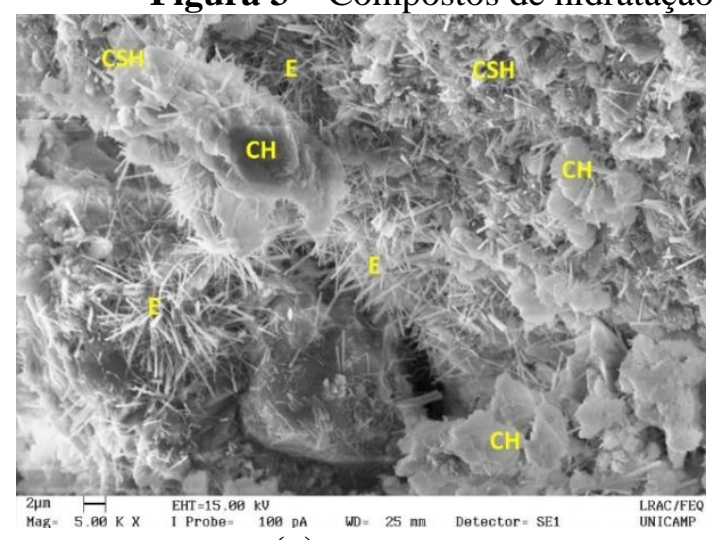

(a)

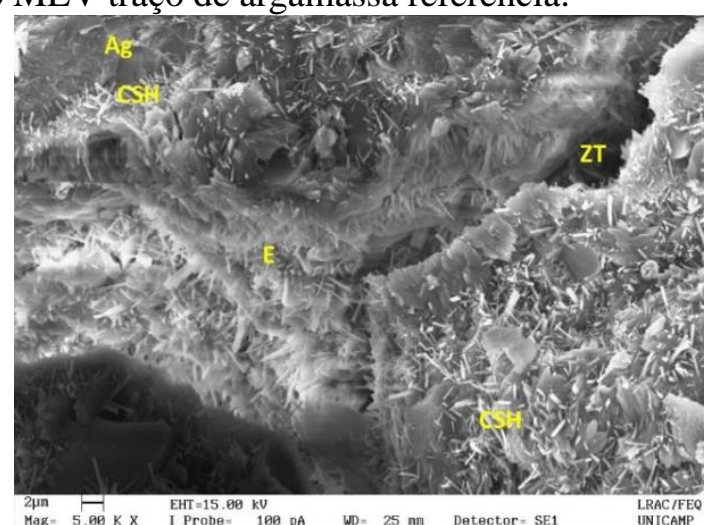

(b)

Fonte: Elaboração dos autores, 2022.

O traço com fíler de cerâmica vermelha também apresentou os produtos de hidratação, etringita, CSH e portlantida, Figura 4 (a). Há o crescimento destes produtos na zona de transição (ZT) agregado pasta, Figura 4 (b).

Figura 4 - Compostos de hidratação MEV argamassa com fíler de cerâmica vermelha.

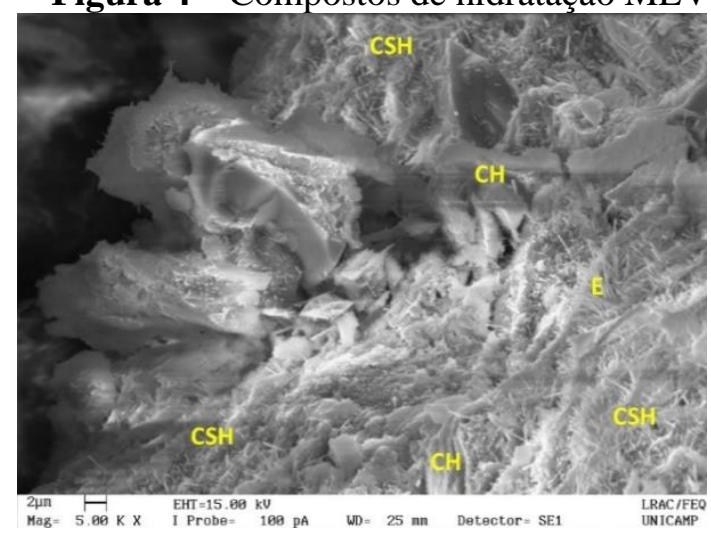

(a)

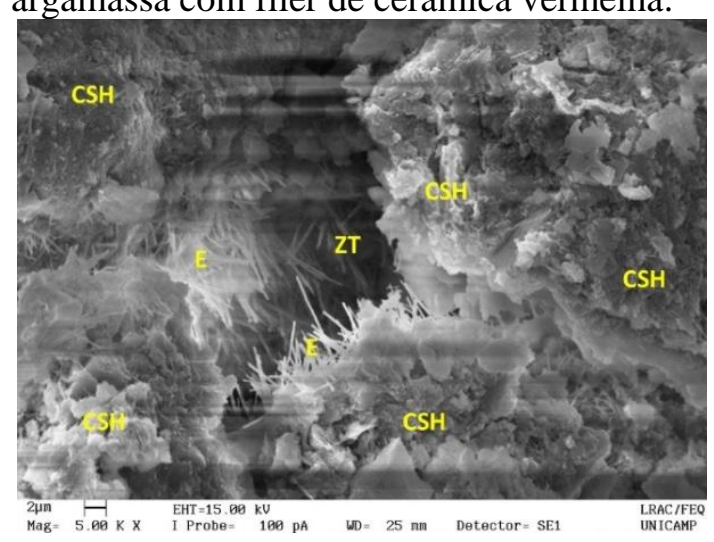

(b)

Fonte: Elaboração dos autores, 2022.

Ao analisar as imagens de MEV para as argamassas de fíler de isoladores de porcelana é visível a zona de transição (ZT) agregado-pasta, Figura 5 (a). Os principais produtos identificados foram o C-S-H e a portlandita $(\mathrm{CH})$, Figura 5 (b). 
Figura 5 - Compostos de hidratação MEV argamassa com fíler de porcelana.

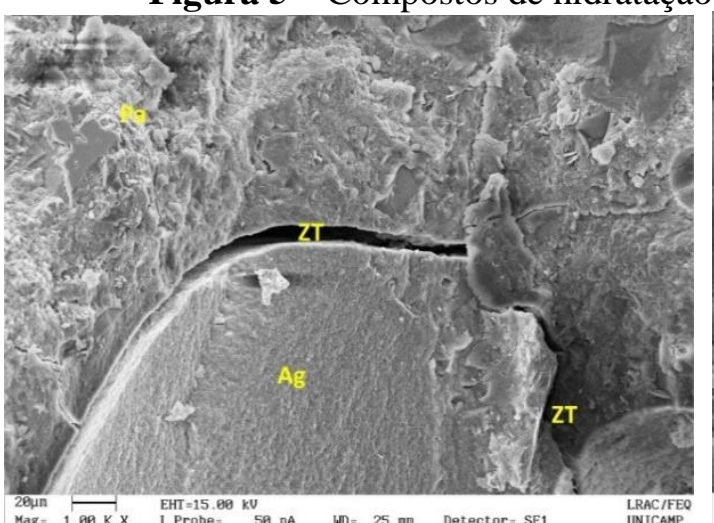

(a)

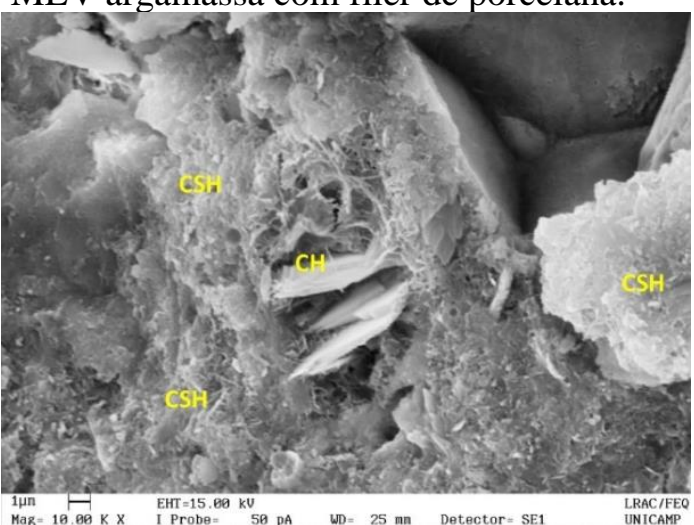

(b)

Fonte: Elaboração dos autores, 2022.

Para o traço com o mix de fílers, cerâmica vermelha e porcelana, foi verificado todos os compostos de hidratação, etringita, C-S-H e CH, Figura 6 (a), além de um vazio capilar (VC), Figura 6 (b) atribuído absorção de água por parte dos fílers e da sílica ativa.

Figura 6 - Compostos de hidratação MEV argamassa com mix de fílers de cerâmica vermelha e de porcelana.

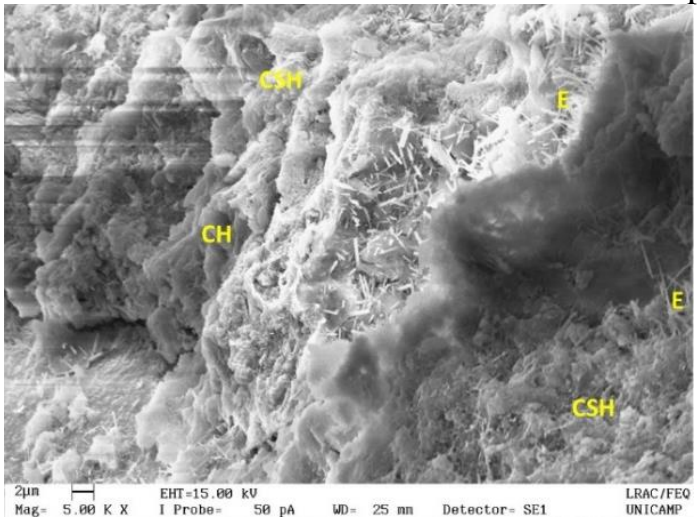

(a)

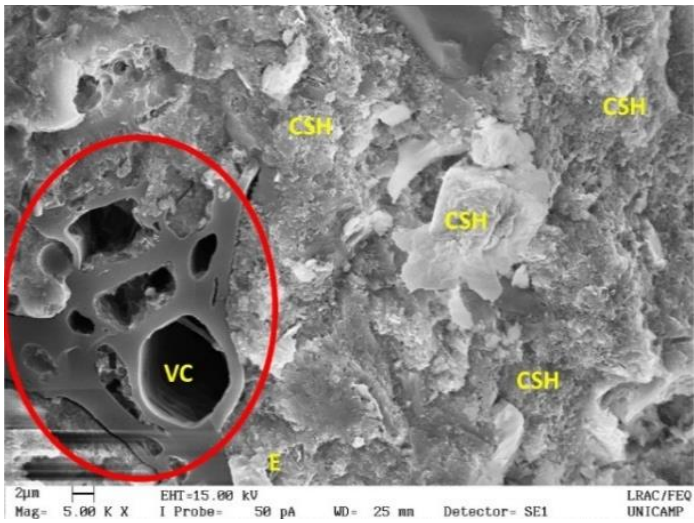

(b)

Fonte: Elaboração dos autores, 2022.

Todos estes produtos de hidratação observados nos diferentes traços de argamassa estão em comum com a bibliografia especialmente na formação dos compostos na zona de transição entre o agregado e a pasta de cimento no concreto conforme Mehta; Monteiro (2008 - p. 43, fig. 2.14 (b)) e Scrivener (1989 - p. 141, fig. 23). Alguns trabalhos acadêmicos também identificaram similaridade nos compostos formados quando da utilização de isoladores elétricos de porcelana (SHIROMA, 2016; CAMPOS, 2018). 


\section{CONCLUSÕES}

O processo de moagem a que os resíduos cerâmicos são submetidos para sua reutilização na construção civil permite de início obter um material alternativo, que quando finamente moído, pode ser incorporado em argamassas e concretos, atuando como fíler pozolânico em matrizes cimentícias alternativas com baixo teor de cimento, pois seu processo de produção envolve a queima em altas temperaturas e suas matérias-primas são similares as do cimento Portland.

Os resíduos de telhas cerâmicas e de isoladores elétricos de porcelana atendem os quesitos iniciais para serem utilizados como material pozolânico em matrizes cimentícias com baixo teor de cimento Portland. Assim, o controle da granulometria destes tipos de fílers permite seu uso, entretanto, recomenda-se a incorporação em conjunto com a sílica ativa, outro material com propriedade pozolânica.

A incorporação destes fílers mostrou ser benéfica, pois ocorreu um aumento de resistência à compressão simples, comparando as idades de 7 e 28 dias, com tendência a evoluir para idades mais avançadas. Destaca-se também a elevada resistência do traço de argamassa com fíler de porcelana que obteve uma resistência de 37,3 MPa aos 28 dias.

Outro destaque pró-utilização da combinação de sílica ativa e fíler, em substituição ao cimento Portland, é a evolução da resistência quando se compara a idade inicial de 7 dias com a final de 28 dias. O traço com fíler cerâmico resultou em aumento de $28,6 \%$ e o traço com mix de fílers a evolução foi de 20,1\%, o que comprova que a cerâmica vermelha aliada a sílica ativa e ao isolador de porcelana possuem, quando utilizados em conjunto, uma atividade pozolânica tardia em comparação ao cimento.

A análise microestrutural, aos 28 dias, mostrou que independentemente dos traços de argamassa há presença dos principais produtos de hidratação, caso do C-S-H, este em maior quantidade devido a grande quantidade de sílica nos componentes da argamassa, portlandita $\mathrm{CH}$, e etringita estando em comum a bibliografia. Assim, a elevação de resistência das argamassas é em relação ao melhor empacotamento dos grãos, atividade pozolânica combinada da sílica ativa e dos fílers cerâmicos e formação dos produtos de hidratação do cimento.

A partir destes dados é comprovada a utilização da combinação de sílica ativa e fílers cerâmicos em substituição ao cimento Portland em matrizes cimentícias com baixo teor de cimento. Por ser um trabalho preliminar na incorporação combinada de sílica ativa e fílers cerâmicos recomenda-se estudos para idades mais avançadas, além de outros tipos de cura, e principalmente com variados teores de combinação de sílica ativa e estes tipos de fílers, além da utilização das matrizes não apenas em argamassas mas em concretos também.

Portanto, a metodologia apresentada neste trabalho tende a ser um legado para próximas pesquisas visando a utilização de resíduos de isoladores elétricos de porcelana e telhas cerâmicas como matrizes cimentícias e sua utilização em argamassas e concretos. Estes dois tipos de 
resíduos cerâmicos devem se somar a outros materiais alternativos com o intuito de reduzir o teor de cimento Portland em argamassas e até em concretos, beneficiando o setor da construção civil em toda a sua cadeia produtiva, e também o meio ambiente, pois têm-se a utilização de resíduos antes descartados e principalmente a diminuição da poluição da indústria cimenteira, proporcionando uma alternativa viável para a diminuição da extração de materiais da natureza para o beneficiamento industrial.

\section{AGRADECIMENTOS}

Para este trabalho agradecemos as seguintes empresas: TecnosilBr pela doação da Sílica Ativa e Cerâmica Santa Terezinha pela doação dos isoladores elétricos de porcelana moídos, ao Laboratório de Estruturas da Faculdade de Engenharia Civil, Arquitetura e Urbanismo da Universidade Estadual de Campinas pela realização dos ensaios com as argamassas e ao Laboratório de Caracterização de Biomassa, Recursos Analíticos e de Calibração da Faculdade de Engenharia Química da Unicamp por realizar os ensaios de MEV/EDS.

\section{REFERÊNCIAS}

ASSOCIAÇÃO BRASILEIRA DE NORMAS TÉCNICAS - ABNT. NBR 7215 - Cimento Portland - Determinação da resistência à compressão. Rio de Janeiro, 1996.

ASSOCIAÇÃO BRASILEIRA DE NORMAS TÉCNICAS - ABNT. NBR 11579 - Cimento Portland - Determinação do índice de finura por meio da peneira $75 \mu \mathrm{m}\left(\mathrm{n}^{\circ} 200\right)$. Rio de Janeiro, 2012.

ASSOCIAÇÃO BRASILEIRA DE NORMAS TÉCNICAS - ABNT. NBR 16372 - Cimento Portland e outros materiais em pó - Determinação da finura pelo método de permeabilidade ao ar (método de Blaine). Rio de Janeiro, 2015.

ASSOCIAÇÃO BRASILEIRA DE NORMAS TÉCNICAS - ABNT. NBR 16605 - Cimento Portland e outros materiais em pó - Determinação da massa específica. Rio de Janeiro, 2017.

BERALDO, A.; SHIROMA, L.; FERREIRA, G. C. S. Compósito de cimento Portland com adição de resíduos de isoladores de porcelana e de Pinus. In: CLB-MCS 2014 - Congresso Luso-Brasileiro de Materiais de Construção Sustentáveis, 2014, Guimarães - Portugal.

Anais[...] Guimarães-PT, 2014.

CAMPOS, M. A. Isoladores elétricos de porcelana na construção civil: Propriedades, pesquisa e aplicação. 1. ed. Riga, Letônia: Novas Edições Acadêmicas, 2018.

CAMPOS, M. A.; PASSOS, L.; ARGOLlO FERRÃO, A. M.; MORENO JUNIOR, A. L. Utilização de fíler cerâmico e sílica ativa na composição de argamassa com baixo teor de cimento. Brazilian Journal of Development, v. 5, p. 9876-9890, 2019.

CARVALHO, C. M. DE. Caracterização de resíduos da indústria cerâmica e seu emprego em argamassas de cimento Portland. 2016. Dissertação (Mestrado em Engenharia de Materiais) - Universidade Federal da Paraíba, João Pessoa, 2016. 
DAL MOLIN, D. C. C. Adições minerais para concreto estrutural, In: ISAIA, G. C. Concreto Ensino, Pesquisa e Realizações. São Paulo, IBRACON, 2005.

DIAS, J. F. Avaliação de Resíduo da Fabricação de Telhas Cerâmicas Para Seu Emprego em Camadas de Pavimento de Baixo Custo. 2004. Tese (Doutorado em Engenharia Civil) Escola Politécnica, Universidade de São Paulo, São Paulo, 2004.

GOUVEIA, F. P. Efeito da incorporação de chamote (resíduo cerâmico queimado) em massa cerâmicas para a fabricação de blocos cerâmicos para o Distrito Federal: um estudo experimental. 2008. Dissertação (Mestrado em Estruturas e Construção Civil) - Departamento de Engenharia Civil e Ambiental, Universidade de Brasília, Brasília, 2008.

MEHTA, P. K.; MONTEIRO, P. J. M. Concreto: Microestrutura, propriedades e materiais. São Paulo, IBRACON, 2008.

NEVILLE, A. M.; BROOKS, J. J. Tecnologia do Concreto. Porto Alegre, Bookman, 2013.

PASSOS, L. Desempenho do concreto leve com agregado cerâmico reciclado em substituição ao agregado natural na execução de elementos estruturais. 2019. Tese (Doutorado em Engenharia Civil) - Faculdade de Engenharia Civil, Arquitetura e Urbanismo, Universidade Estadual de Campinas, Campinas, 2019.

PEREIRA, V. M. Argamassas autonivelantes com resíduos de porcelana. 2019. Tese (Doutorado em Engenharia Civil) - Faculdade de Engenharia Civil, Arquitetura e Urbanismo, Universidade Estadual de Campinas, Campinas, 2019.

PORTELLA, K. F.; JOUKOSKI, A.; FRANCK, R.; DERKSEN, R. Reciclagem secundária de rejeitos de porcelana elétrica em estruturas de concreto: determinação do desempenho sob envelhecimento acelerado. CERÂMICA, 52., 2006. 155-167 p.

REBMANN, M. S. Durabilidade de concretos estruturais com baixo consumo de cimento Portland e alta resistência, 2011. Dissertação (Mestrado em Engenharia Civil), Escola de Engenharia de São Carlos da Universidade de São Paulo, São Carlos, 2011.

SALES, A. T. C.; ALFERES FILHO, R. DOS S. Efeito do pó de resíduo cerâmico como adição ativa para o concreto. Ambiente Construído, Porto Alegre, v. 14, n. 1, p. 113-125, jan./mar. 2014.

SÃO PAUlO. Polos cerâmicos do estado de São Paulo. Disponível em http://dadosenergeticos.energia.sp.gov.br/Portalcev2/Intranet/mineracao/mapas/mapa_polos_cer amicos.jpg. Acesso 19 jul. 2021.

SCRIVENER, K. L. The Microstructure of Concrete. In: SKALNY, J. P. Materials science of concrete. Westerville: The American Ceramic Society, 1989. 334 p. p. 127-162.

SHIROMA, L. Caracterização de resíduo de porcelana de concessionárias de energias como substituição ao cimento Portland. 2016. Tese (Doutorado em Engenharia Agrícola) - Faculdade de Engenharia Agrícola, Universidade Estadual de Campinas, Campinas, 2016.

SOARES, M. da S. Argamassa convencional e colante com uso de isolador de resíduo de porcelana. 2016. Dissertação (Mestrado em Engenharia Civil) - Faculdade de Engenharia Civil, Arquitetura e Urbanismo, Universidade Estadual de Campinas, Campinas, 2016. 
WADA, P. H. Estudo da incorporação de resíduo de cerâmica vermelha na composição de concreto para uso em estacas moldadas in loco. 2010. Dissertação (Mestrado em Engenharia Civil) - Faculdade de Engenharia, Universidade Estadual Paulista, Ilha Solteira, 2010.

Recebido em: 15/01/2022

Aprovado em: 05/02/2022

Publicado em: 10/02/2022 